\title{
Kamil Gemra
}

\section{Świadomość funkcjonowania green bonds na polskim rynku obligacji korporacyjnych}

Streszczenie: Inwestycje związane ze zrównoważonym rozwojem zazwyczaj mają charakter długoterminowy. Zapewnienie odpowiedniego kapitału jest niezbędne, aby móc je realizować. Jednym z ciekawych instrumentów finansowych, zdolnych do sprostania tym oczekiwaniom, są tzw. zielone obligacje ( $g r e e n$ bonds). Pierwsza zielona obligacja została nazwana „obligacją klimatyczną" i została wyemitowana przez Europejski Bank Inwestycyjny (EBI) w 2007 roku. Od tego momentu rynek ten zaczął się rozwijać, a Polska ma istotny wkład w jego rozwój, ponieważ stała się pierwszym krajem, który wyemitował zielone obligacje państwowe w grudniu 2016 r. Celem artykułu jest zbadanie świadomości funkcjonowania oraz planów dotyczących green bonds wśród emitentów obligacji, którzy wprowadzili do obrotu giełdowego na rynku Catalyst tradycyjne obligacje korporacyjne. Cel ten został osiągnięty za pomocą badania ankietowego emitentów obligacji notowanych na rynku Catalyst. Analiza wskazała, że emitenci coraz częściej spotykają się z zagadnieniem ESG i chcą wdrażać jego założenia do swojej strategii rozwoju, a dodatkowo, większość ankietowanych w przyszłości będzie chciała wyemitować zielone obligacje, co może spopularyzować ten instrument finansowy.

Słowa kluczowe: obligacje, green bonds, zielone obligacje, obligacje korporacyjne, rynek kapitałowy

\section{Awareness of the green bond market on Polish corporate bonds}

Summary: Investments related to sustainable development are usually of a long-term nature. Providing adequate capital is necessary to be able to implement them. One of the interesting financial instruments capable of meeting these expectations are the so-called Green bonds. The first green bond was called a "climate bond" and was issued by the Euro- 
pean Investment Bank (EIB) in 2007. From that moment on, the market began to develop, and Poland has made a significant contribution to the development of the green bond market, as it became the first country to issue green government bonds in December 2016. The aim of the article is to examine the awareness and plans for green bonds among bond issuers who introduced traditional corporate bonds to trading on the Catalyst market. This goal will be achieved through a survey of bond issuers listed on the Catalyst market. The analysis showed that issuers are increasingly confronted with the issue of ESG and want to implement its assumptions into their development strategy, and in addition, most of the respondents will want to issue green bonds in the future, what can popularize this financial instrument.

Keywords: green bonds, corporate bonds, capital market

\section{JEL: G10}

Kwestie środowiskowe, społeczne i ładu korporacyjnego (ESG - environmental, social, and governance) są coraz częściej uwzględniane w polityce korporacyjnej. Są one związane z ideą zrównoważonego rozwoju gospodarczego respektującego środowisko naturalne. Zagadnienia te dyskutowane są od dawna na forum międzynarodowym, jednocząc rządy, międzynarodowe oraz krajowe instytucje i organizacje, we wspólnych inicjatywach podejmowanych na rzecz ochrony środowiska. Jednakże wdrożenie idei zrównoważonej i bardziej ekologicznej gospodarki wymaga znacznych nakładów finansowych. W związku z tym, w cały proces musieli zaangażować się uczestnicy rynku finansowego.

Inwestycje środowiskowe wymagają zwykle długoterminowego finansowania. Dobrym źródłem pozyskiwania tych środków jest rynek kapitałowy, a także rynek instrumentów dłużnych, jako alternatywa dla kredytów bankowych czy emisji akcji. Odpowiedzią na te potrzeby są tzw. zielone obligacje ( green bonds) - instrumenty dłużne, które finansują wyłącznie projekty przynoszące korzyści dla środowiska, a zatem mogą zmniejszyć negatywny wpływ działalności gospodarczej na zmiany klimatu.

W praktyce rynek tzw. zielonych obligacji (green bonds) pojawił się w latach 2007-2008 wraz z pierwszymi emisjami przeprowadzonymi przez Europejski Bank Inwestycyjny oraz Bank Światowy. Należy jednak zauważyć, że nadal w porównaniu z konwencjonalnym rynkiem obligacji, rynek tego rodzaju obligacji jest wciąż stosunkowo niewielki (Elhers, Hacker, 2017), ale od pierwszej takiej emisji w 2007 r. ich znaczenie zaczęło mocno wzrastać. Emitenci z sektora prywatnego dołączyli do tego rynku w latach 2013-2014. Z kolei pierwsze skarbowe zielone obligacje (sovereign green bonds) zostały wyemitowane dopiero pod koniec 2016 r. Co ciekawe, emitentem tych instrumentów była Polska, wpisując się tym samym w historię rozwoju światowego rynku finansowego (Mosionek-Schweda, Szmelter, 2018).

Celem artykułu jest zbadanie świadomości funkcjonowania oraz planów dotyczących green bonds wśród emitentów obligacji, którzy wprowadzili do obrotu giełdowego na rynku Catalyst tradycyjne obligacje korporacyjne. Cel ten zostanie osiągnięty za pomocą 
sondażu diagnostycznego przeprowadzonego wśród emitentów obligacji notowanych na rynku Catalyst.

\section{Istota zielonych obligacji}

Jedną z najważniejszych innowacji finansowych w obszarze zrównoważonych finansów w ciągu ostatnich dziesięciu lat był rozwój rynków obligacji ekologicznych i innych rynków „obligacji oznaczonych” (np. obligacji zrównoważonego rozwoju i obligacji społecznych). Obligacje ekologiczne mają zwykle taką samą strukturę jak tradycyjne obligacje o ratingu inwestycyjnym, z wyjątkiem tego, że obligacja zawiera klauzulę „wykorzystania dochodów”, która stanowi, że finansowanie zostanie wykorzystane na ekologiczne inwestycje. Oznacza to, że w przeciwieństwie do obligacji „waniliowych”, które finansują ogólny kapitał obrotowy emitenta, obligacje ekologiczne powinny być wykorzystywane do finansowania lub refinansowania wyłącznie zielonych projektów lub aktywów. Jednocześnie nabywca obligacji zielonych pożycza pieniądze emitentowi, co oznacza, że inwestor nie jest bezpośrednio narażony na ryzyko finansowe konkretnych projektów, które finansują obligacje ekologiczne (Maltais, Nykvist, 2021). Zielone obligacje są instrumentami dłużnymi o stałym oprocentowaniu. Kwota kapitału jest wypłacana inwestorom po dacie wykupu, natomiast odsetki są wypłacane według formuły kuponowej w całym okresie ważności (Brzozowska, 2017). Pierwsza zielona obligacja została nazwana „obligacją klimatyczną” i została wyemitowana przez Europejski Bank Inwestycyjny (EBI) w 2007 roku. Od tego momentu rynek ten zaczął się rozwijać poszerzając się o nowe rodzaje emitentów, a także niniejszy instrument stał się coraz bardziej popularny w różnych rejonach geograficznych. Polska ma istotny wkład w rozwój tego rynku, ponieważ stała się pierwszym krajem, który wyemitował zielone obligacje państwowe w grudniu 2016 r. Następnie zrobiła to Francja w styczniu 2017 r. Z kolei agencja rządowa Stanów Zjednoczonych, Fannie Mae, przeprowadziła w 2017 roku największą emisję zielonych obligacji o wartości 24,9 mld USD zabezpieczonych hipoteką. W czerwcu 2017 r. Malezja wprowadziła na rynek pierwszą na świecie zieloną obligację islamską "green Sukuk”, aby sfinansować swój rozwój z poszanowaniem zasad zrównoważonego rozwoju. Co więcej, znacząco powiększają się również rodzaje emitentów, w tym organizacje ponadnarodowe (tj. Bank Światowy i Międzynarodowy Fundusz Walutowy), banki rozwoju (tj. ADB i AfDB), banki komercyjne (tj. Bank of America i HSBC) czy niebankowe instytucje finansowe, takie jak fundusze nieruchomościowe typu REIT, np. Regency Centers Corporation i Link REIT. Co ciekawe, zielone obligacje emitują także wielkie międzynarodowe korporacje, takie jak Apple czy Tesla. Jeżeli chodzi o Polskę to warto wspomnieć, że emisją zielonych obligacji są zainteresowane samorządy, które dysponując coraz to bardziej ograniczonymi środkami własnymi, liczą na taką dedykowaną formę pozyskania kapitału. Według Thomson Reuters, roczna wielkość emisji zielonych obligacji osiągnęła 155,5 mld USD w 2017 r. i nabrała rozpędu, aby osiągnąć cel 1 biliona USD w 2020 r. (Tang, Zhang, 2020). Zielone obligacje korporacyjne stają się coraz bardziej popularne w ostatnich latach - Morgan Stanley nazywa tę ewolucję „zielonym boomem obligacji” (Flammer, 2021). Co więcej, analitycy twierdzą, że do 2050 r. musimy inwestować 3,95 bln USD rocznie w niskoemisyjne projekty energetyczne, transportowe 
i budowlane (Jones i in., 2020), zatem kapitał z tychże instrumentów będzie wykorzystywany coraz częściej. W materiałach podsumowujących 2020 rok zwraca się uwagę, że rynek ten mógł mieć wartość od 700 mld dolarów do 1,4 biliona dolarów.

Pomimo tego, że rynek zielonych obligacji szybko się rozwija, nadal toczą się spory dotyczące definicji, wytycznych i nadawania określonych cech takim obligacjom. Aktualnie istnieją dwa „standardy” zielonych obligacji: Green Bond Principles (GBP) oraz Climate Bond Initiative (CBI). GBP przy określaniu obligacji jako zielonych bierze pod uwagę cztery kryteria, takie jak: wykorzystanie wpływów, proces oceny i wyboru projektów, zarządzanie wpływami oraz raportowanie. CBI skupia się z kolei na konkretnym sektorze z jakiego pochodzi emitent i wyznacza kryteria dla danego sektora, aby tak wyemitowane obligacje można było uznać za zielone. Oba standardy są powszechnie uznawane przez rynek.

\section{Zielone obligacje w literaturze naukowej}

Warto zadać pytanie - jakie są zatem powody emisji tego typu obligacji? W literaturze można zidentyfikować trzy potencjalne powody. Po pierwsze, zielone obligacje mogą służyć jako wiarygodny sygnał zaangażowania firmy wobec środowiska (argument sygnalizacyjny). Taki sygnał może być cenny, ponieważ inwestorom często brakuje wystarczających informacji o zaangażowaniu firmy w ochronę środowiska (Lyon, Maxwell, 2011).

Po drugie, emisja zielonych obligacji może być formą greenwashingu - czyli praktyki składania nieuzasadnionych lub wprowadzających w błąd twierdzeń dotyczących zaangażowania firmy w ochronę środowiska. W tym duchu firmy emitowałyby zielone obligacje, aby przedstawiać się jako odpowiedzialne za środowisko, ale bez podejmowania namacalnych działań, co jest wspomnianym argumentem greenwashingu. Po trzecie, jeśli inwestorzy w obligacje ekologiczne są skłonni wymienić zyski finansowe na korzyści społeczne, firmy mogą emitować obligacje ekologiczne, aby uzyskać tańsze finansowanie, co jest argumentem dotyczącym kosztu kapitału (Lyon, Montgomery, 2015).

Literatura dotycząca zielonych obligacji skupia się w dużej mierze na dwóch wątkach. Pierwszym aspektem jest zrozumienie, czy istnieje systematyczna różnica cen między obligacjami konwencjonalnymi, a podobnymi obligacjami zielonymi, tj. premia za obligacje ekologiczne. Ten nurt literatury wskazuje na istnienie negatywnej premii ekologicznej w ostatnim czasie (Petrova, 2016; Hachenberg, Schiereck, 2018; Gianfrate, Peri, 2019; Kapraun et al., 2021)

Z kolei Pham (2016) był pierwszym badaczem analizującym zmienność rynku obligacji zielonych przy użyciu danych o dziennych cenach zamknięcia indeksów zielonych obligacji S\&P, w okresie od kwietnia 2010 do kwietnia 2015. Nanayakkara i Colombage (2019) stwierdzili, że obligacje ekologiczne są notowane z premią 63 punktów bazowych w porównaniu z emisją obligacji korporacyjnych. Broadstock i Cheng (2019) extracting dynamic conditional correlations (DCC odkryli, że korelacje między zielonymi i „czarnymi”, tj. konwencjonalnymi, obligacjami są zmienne w czasie i są wrażliwe na: zmienność rynków finansowych; niepewność polityki gospodarczej; ryzyko operacyjne biznesu; ceny ropy naftowej i unikalnie skonstruowane miary pozytywnego i negatywnego sentymentu 
do zielonych obligacji, oparte na wiadomościach i komunikatach na ten temat. Hyun z pozostałymi członkami zespołu (2020) stwierdzają, że porównanie premii dochodowych skorygowanych o płynność obligacji ekologicznych z syntetycznymi obligacjami konwencjonalnymi wskazuje, że przeciętnie nie ma solidnej i znaczącej premii dochodowej ani dyskonta w przypadku obligacji ekologicznych. Do tego ciekawe badanie (Reboredo, 2018) pokazuje, że ceny zielonych obligacji słabo współgrają z rynkami surowców energetycznych. Z kolei Gormus z zespołem (2018) pokazali, że rynki energii mają wpływ na cały rynek obligacji wysokodochodowych (high-yeld). Pojawiają się też analizy mówiące o tym, że wyniki inwestycji w obligacje ekologiczne są lepsze niż wyniki inwestycji w obligacje konwencjonalne, ale przewaga ta maleje z czasem (Kanamura, 2020).

Drugi nurt literatury skupia się na identyfikacji czynników cenowych zielonych obligacji. Empirycznie udokumentowane czynniki cenowe obejmują rating kredytowy i sektor (Hachenberg i Schiereck, 2018; Gianfrate i Peri, 2019), płynność finansową (Febi i inni, 2018), ceny obligacji skarbowych i korporacyjnych (Reboredo, 2018), czy też ich określenie jako zielone obligacje (Karpf i Mandel, 2018).

Warto też zwrócić uwagę, że Więckowska (2013) wskazuje, iż zielone obligacje pełnią funkcję standardowych narzędzi finansowych, umożliwiają inwestorom instytucjonalnym inwestowanie w zielone branże. Ponadto badania sugerują, że poza konwencjonalnym wsparciem polityki gospodarczej, zobowiązania klimatyczne mogą przyczynić się do globalnej redukcji emisji poprzez zachęcanie do większego finansowania zielonymi obligacjami projektów energii odnawialnej, niezbędnych do osiągnięcia celów redukcji emisji (Tolliver i inni, 2020).

\section{Analiza otrzymanych danych}

Osiągnięcie celu artykułu było możliwe przy pomocy sondażu diagnostycznego przeprowadzonego wśród emitentów obligacji notowanych na rynku Catalyst. Internetowe badanie zostało przeprowadzone w terminie od 10.02.2021 do 10.03.2021. Ankieta została wysłana do 74 emitentów obligacji. Na pytania dotyczące zielonych obligacji odpowiedziało 12 spółek, zatem osiągnięto zwrot na poziomie 16,2 proc.

Na początku ankiety zadano pytania metryczkowe. Okazało się, że 8 emitentów reprezentuje spółki prywatne, a 4 spółki z udziałem Skarbu Państwa. Ważną kwestią jest to, że 11 emitentów zauważyło, iż w ich opinii w ciągu ostatnich pięciu latach wzrosła skala inwestycji dokonywanych z uwzględnieniem czynników ESG. Ponadto 7 emitentów wskazało, że spotkało się z aktywnością inwestycyjną na rynku polskim funduszy etycznych, których zasady inwestowania zakładają uwzględnianie wszystkich lub wybranych zagadnień z obszaru ESG. Ciekawych informacji dostarcza rysunek 1, na którym przedstawiono odpowiedzi na pytanie, czy w kontaktach z obligatariuszami pytają oni o kwestie związane z ESG. Ankietowani określali to w skali od 1 od 5, gdzie 1 oznaczało, że nie pytają, a 5 bardzo często pytają.

Odpowiedzi wskazują, że w przypadku 5 firm często lub bardzo często zdarzają się pytania o ESG. Jednocześnie 5 firm wskazało, że w kontaktach z obligatariuszami nie pytają oni jeszcze o ESG. Co ciekawe, głębsza analiza odpowiedzi wskazuje, że dwie firmy pry- 


\section{Rysunek 1 Odpowiedzi na pytanie czy w kontaktach z obligatariuszami pytają oni o kwestie związane z ESG}

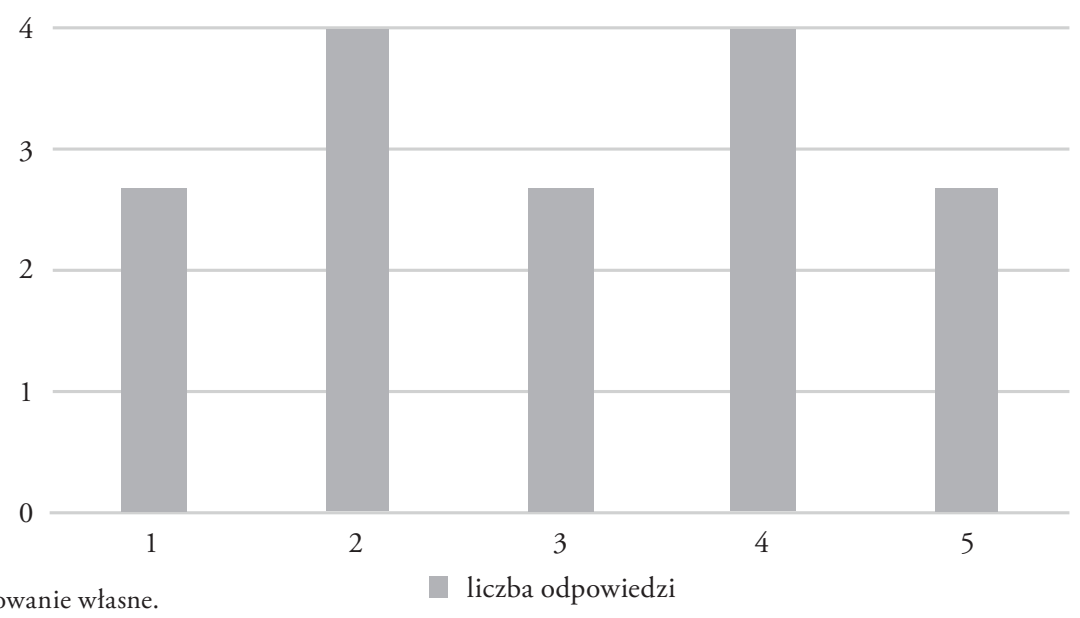

Źródło: opracowanie własne.

watne zaznaczyły wartość 5 , a z kolei wartość 4 zaznaczyły 2 firmy prywatne oraz jedna firma z udziałem Skarbu Państwa. Zatem można wysnuć wniosek, że z badanej grupy to firmy prywatne częściej spotykają się z tematyką związaną z ESG, gdy spotykają się z potencjalnymi obligatariuszami.

$\mathrm{Na}$ kolejnym wykresie zaprezentowano dane, czy zagadnienia z obszaru ESG znajdują się w strategii rozwoju danych emitentów obligacji korporacyjnych notowanych na rynku Catalyst. Żadna firma nie wskazała, że uwzględnia wszystkie zalecenia, ale zdecydowana większość wskazuje, że chce w najbliższych latach zwiększyć liczbę zagadnień z zakresu ESG w swojej strategii rozwoju.

W związku z pytaniem o implementacje zagadnień z zakresu ESG w strategii rozwoju, w ankiecie zadano też pytanie dotyczące tego, co mogłoby skłonić emitentów do uwzględniania zagadnień z obszaru ESG na etapie pozyskiwania kapitału z emisji obligacji. Dane

\section{Rysunek 2 Odpowiedzi na pytanie czy zagadnienia (dobre praktyki) z obszaru ESG są częścią strategii rozwoju Państwa firmy?}

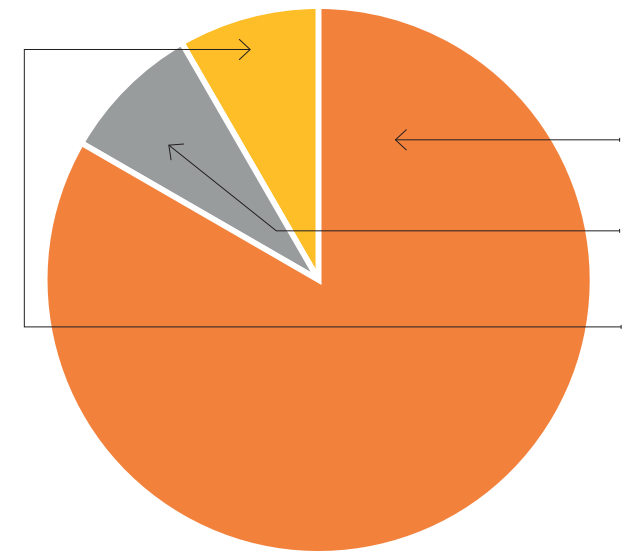

tak, uwzględniamy wszystkie zagadnienia z obszaru ESG (0)

tak, uwzględniamy wybrane zagadnienia z obszaru ESG, ale w najbliższych 2-3 latach chcemy zwiększyć ich liczbę (10)

nie, ale uwzględnianie zagadnień z obszaru ESG w naszej strategii planujemy w okresie najbliższych 2-3 lat (1) nie i nie zamierzamy ich uwzględniać w naszej strategii rozwoju (1) 


\section{Rysunek 3 Co mogłoby Państwa skłonić do tego, aby w większym stopniu} uwzględniać zagadnienia z obszaru ESG na etapie pozyskiwania kapitału z emisji obligacji?

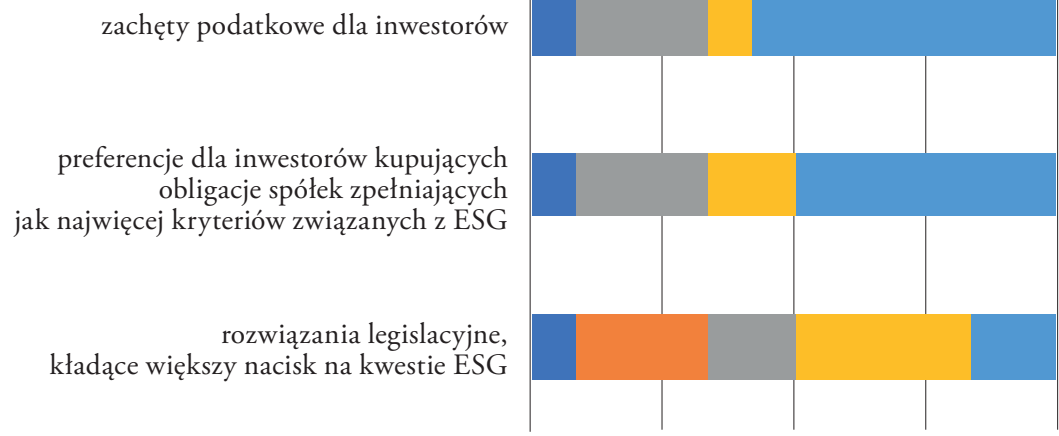

Źródło: opracowanie własne.

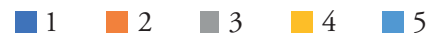

te przedstawia rysunek 3. Ankietowani w odpowiedzi stosowali ocenę w skali od 1 do 5 , gdzie 1 to ocena najniższa, a 5 najwyższa.

Zdecydowanie przedstawiciele spółek wskazali, że kluczowe byłyby zachęty podatkowe dla inwestorów oraz preferencje dla inwestorów kupujących obligacje spółek, które spełniałyby jak najwięcej kryteriów związanych z ESG. Ważne w ocenie ankietowanych są również rozwiązania legislacyjne, które kładłyby większy nacisk na ESG.

Na zakończenie ankietowani zostali zapytani o to, czy chcą wyemitować zielone obligacje. Odpowiedzi na to pytanie prezentuje rysunek 4. Jeden emitent wskazał, że ma wyemitowane zielone obligacje, natomiast 7 zadeklarowało, że chce to zrobić w najbliższych 2-3 latach. Zatem można przypuszczać, że zielone obligacje, zgodnie ze światowymi trendami, mogą być również coraz popularniejsze wśród polskich emitentów obligacji korporacyjnych.

\section{Rysunek 4 Czy mają Państwo wyemitowane tzw. zielone obligacje}

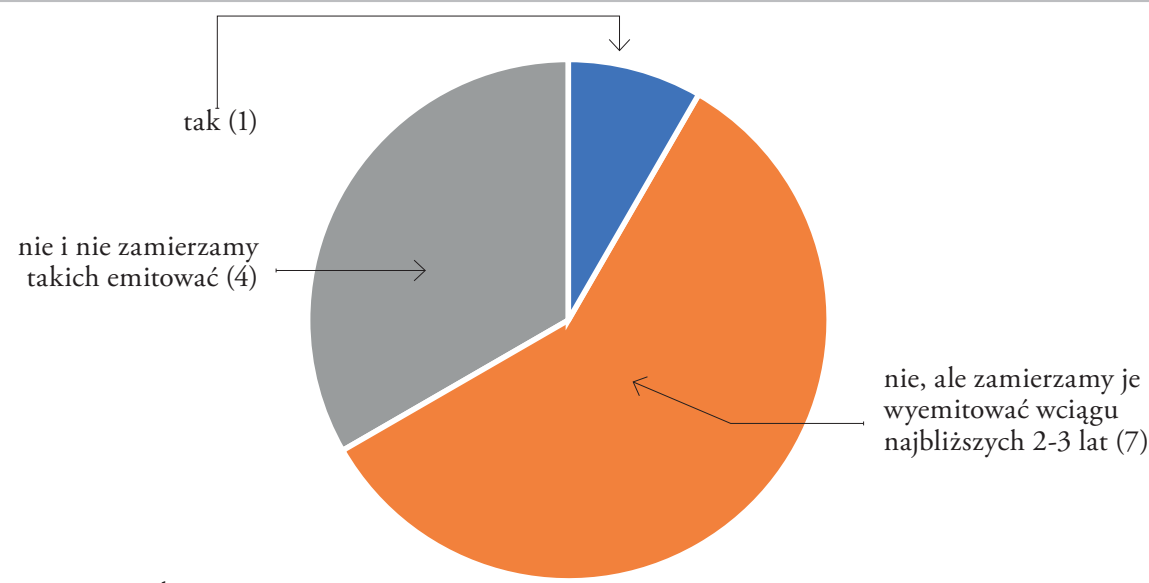




\section{Podsumowanie}

Tendencje obserwowane we współczesnym świecie wskazują, że nieprzestrzeganie zasad zrównoważonego rozwoju powodować będzie wzrost ryzyka finansowego przedsiębiorstwa. Może się okazać, że niektóre branże będą miały problemy z pozyskiwaniem kapitału. Zielone obligacje są instrumentem finansowym, który odpowiada na obecne oczekiwania rynkowe. Na podstawie przeprowadzonego badania ankietowego wśród emitentów obligacji notowanych na rynku Catalyst należy zauważyć, że firmy prywatne dostrzegają rosnące zainteresowanie tematyką ESG wśród potencjalnych obligatariuszy. Spółki wskazują, że chcą coraz więcej zagadnień związanych ze zrównoważonym rozwojem implementować do swoich strategii rozwoju. Ponadto zwracają uwagę, że potrzeba rozwiązań legislacyjnych, które skłaniałyby to większego nacisku na ESG przy emisjach obligacji. W skłonieniu emitentów do zwracania uwagi na ESG przy emisjach obligacji mogłyby pomóc też ulgi i zachęty podatkowe oraz inne preferencje dla inwestorów. Ciekawe jest to, że większość badanych firm chce w przyszłości wyemitować zielone obligacje, zatem może się okazać, że instrument ten stanie się popularny wśród krajowych emitentów obligacji korporacyjnych.

\section{Bibliografia:}

1. Broadstock D.C., Cheng, L.T.W. (2019), Time-varying relation between black and green bond price benchmarks: Macroeconomic determinants for the first decade, "Finance Research Letters", 29, s. 17-22, https://doi.org/https://doi.org/10.1016/j.frl, 2019.02.006

2. Brzozowska K. (2017), Sustainable Development Idea in the Bond Market, Prace Naukowe Uniwersytetu Ekonomicznego we Wrocławiu, 478, s. 70-80, https://doi.org/10.15611/pn.2017.478.06

3. Elhers T., Packer F. (2017), Green bond finance and certification, "BIS Quarterly Review", September, s. 89-104.

4. Febi W., Schäfer D., Stephan A., Sun C. (2018), The impact of liquidity risk on the yield spread of green bonds, "Finance Research Letters", 27, s. 53-59, https://doi.org/https://doi.org/10.1016/j.frl., 2018.02.025

5. Flammer C. (2021), Corporate green bonds, "Journal of Financial Economic", https://doi.org/10.1016/j.jfineco, 2021.01.010.

6. Gianfrate G., Peri M. (2019), The green advantage: Exploring the convenience of issuing green bonds, "Journal of Cleaner Production", 2019, s. 127-135, https://doi.org/https://doi.org/10.1016/j.jclepro, 2019.02.022

7. Gormus A., Nazlioglu S., Soytas U. (2018), High-yield bond and energy markets,"Energy Economic", s. 69, 101-110, https://doi.org/https://doi.org/10.1016/j.eneco 2017.10.037

8. Hachenberg B., Schiereck D. (2018), Are green bonds priced differently from conventional bonds?, "Journal of Asset Management", 19(6), s. 371-383, https://doi.org/10.1057/s41260-018-0088-5

9. Hyun S., Park D., Tian S. (2020), The price of going green: the role of greenness in green bond markets, "Accounting \& Finance", 60(1), s. 73-95, https://doi.org/https://doi.org/10.1111/acfi.12515

10. Jones R., Baker T., Huet K., Murphy L., Lewis N. (2020), Creating ecological deficit with debt: The practical and political concerns with green bonds, "Geoforum", 114 (June), s. 49-58, https://doi.org/10.1016/j.geoforum.2020.05.014 
11. Kanamura T. (2020), Are green bonds environmentally friendly and good performing assets?, "Energy Economics", s. 88, 104767, https://doi.org/10.1016/j.eneco.2020.104767

12. Kapraun J., Latino C., Scheins C., Schlag C. (2021), Which Bonds Trade at a Green Bond Premium?, https://www.bundesbank.de/de/publikationen/berichte/monatsberichte

13. Karpf A., Mandel A. (2018), The changing value of the 'green' label on the US municipal bond market, s. 161-165, https://doi.org/10.1038/s41558-017-0062-0

14. Lyon T.P., Maxwell J.W. (2011), Greenwash: Corporate Environmental Disclosure under Threat of Audit,"Journal of Economics \& Management Strategy", 2010, (1), s. 3-41, https://doi.org/https://doi. org/10.1111/j.1530-9134.2010.00282.x

15. Lyon T.P., Montgomery A.W. (2015), The Means and End of Greenwash, Organization \& Environment, 28(2), s. 223-249, https://doi.org/10.1177/1086026615575332

16. Maltais A., Nykvist B. (2021), Understanding the role of green bonds in advancing sustainability, "Journal of Sustainable Finance and Investment", 11(3), s. 233-252, https://doi.org/10.1080/20430795.2020.172 4864

17. Mosionek-Schweda M., Szmelter M. (2018), Zielone obligacje - nowy instrument finansowania inwestycji polskiego rzadu, Prace Naukowe Uniwersytetu Ekonomicznego we Wrocławiu, s. 532, 215-224, https://doi.org/10.15611/pn.2018.532.21

18. Nanayakkara M., Colombage S. (2019), Do investors in Green Bond market pay a premium? Global evidence, "Applied Economics", 51(40), s. 4425-4437, https://doi.org/10.1080/00036846.2019.1591611

19. Petrova A. (2016), Green Bonds: Lower Returns or Higher Responsibility?, Radboud University, Nijmegen School of Management, Master Thesis, s. 1-47.

20. Pham L. (2016), Is it risky to go green? A volatility analysis of the green bond market, "Journal of Sustainable Finance \& Investment”, 6(4), s. 263-291, https://doi.org/10.1080/20430795.2016.1237244

21. Reboredo J.C. (2018), Green bond and financial markets: Co-movement, diversification and price spillover effects, "Energy Economics", 74, s. 38-50, https://doi.org/https://doi.org/10.1016/j.eneco.2018.05.030

22. Tang D.Y., Zhang Y. (2020), Do shareholders benefit from green bonds?, "Journal of Corporate Finance", December 2020, vol. 61, 101427, https://doi.org/10.1016/j.jcorpfin.2018.12.001

23. Tolliver C., Keeley A.R., Managi S. (2020), Policy targets behind green bonds for renewable energy: Do climate commitments matter, "Technological Forecasting and Social Change", s. 157 (October 2019), 120051, https://doi.org/10.1016/j.techfore.2020.120051

24. Więckowska M. (2013), The role bonds in financing climate resilient economy, "Copernican Journal of Finance \& Accounting", 2(1), https://doi.org/10.12775/cjfa.2013.011

dr Kamil Gemra, Instytut Finansów Korporacji i Inwestycji, Szkoła Główna Handlowa wWarszawie, kgemra@sgh.waw.pl ORCID: 0000-0001-5292-2363 
6. Cavallo A., Ghezzi A., Dell'Era C., Pellizzoni E. (2019), Fostering digital entrepreneurship from startup to scaleup: The role of venture capital funds and angel groups, "Technological Forecasting and Social Change", No. 145, p. 24-35.

7. Ebben J., Johnson A. (2006), Bootstrapping in Small Firms: An Empirical Analysis of Change Over Time, "Journal of Business Venturing", No. 21, p. 851-865.

8. Joshi M.K. (2018), Crowdfunding For Startups in India, "Aweshkar Research Journal”, No. 24(1), p. $37-59$.

9. Kogut J. (2017), Finansowe oraz pozafinansowe formy wsparcia startupów w Polsce, „Zarządzanie Finansami i Rachunkowość", nr 5(2), s. 29-38.

10. Kotha R., George G. (2012), Friends, family, or fools: Entrepreneur experience and its implications for equity distribution and resource mobilization, "Journal of Business Venturing", No. 27, p. 525-543.

11. Kowalczyk I. (2020), Start-up jako przejaw innowacyjnej przedsiębiorczości w Polsce, „Studia Ekonomiczne, Prawne i Administracyjne", nr 1, s. 63-77.

12. Krysztofiak-Szopa J., Wisłowska M. (2019), Polskie Startupy. Raport 2019, Warszawa, Fundacja Startup Poland.

13. Matuszczyk K. (2019), Niepoważne kariery za poważne pieniądze? Blaski i cienie kariery w startupach przetomowe zmiany na rynku pracy w Polsce, Warszawa.

14. Mikołajczyk K., Nawojczyk D. (2013), Startup po polsku. Jak zatożyć i rozwijać dochody biznesu, Gliwice, Helion.

15. Neuberger D., Räthke-Döppner S. (2013), Leasing by small enterprises, “Applied Financial Economics”, No. 23(7), p. 535-549.

16. Ries E. (2012), Metoda Lean Startup. Wykorzystaj innowacyjne narzędzia i stwórz firmę, która zdobędzie rynek, Gliwice, Helion.

17. Rosado-Serrano A., Paul J., Dikova D. (2018), International franchising: A literature review and research agenda, "Journal of Business Research", No. 85, p. 238-257.

18. Smolarek M., Dzieńdziora J. (2011), Wybrane zewnętrzne źródta finansowania rozwoju matych i średnich przedsiębiorstw w Polsce, „Zeszyty Naukowe Wyższej Szkoły Humanitas. Zarządzanie”, nr 2/2011, s. 7-25.

19. Tomaszewski A. (2019), Agencje rządowe a wspieranie start-upów w państwach, w: Systemy wsparcia startupów w Europie Środkowo-Wschodniej, E. Pawęta, M. Pietrzak, T. Pilewicz (red.), Warszawa, SGH, s. $407-411$.

20. White B.A., Dumay J. (2017), Business angels: a research review and new agenda, "Venture Capital", p. $183-216$.

Patrycja Marzec, Uniwersytet Marii Curie-Skłodowskiej w Lublinie, Wydział Ekonomiczny, Katedra Zarządzania, patrycja.marzec@poczta.umcs.pl, ORCID: 0000-0001-7593-6901

Jan Braun, Uniwersytet Marii Curie-Skłodowskiej w Lublinie, Wydział Ekonomiczny, Katedra Finansów Publicznych, jan.braun@poczta.umcs.pl, ORCID: 0000-0002-5762-0046 